\title{
Effect of habitat architecture on mobile benthic macrofauna associated with patches of barnacles and ascidians
}

\author{
Eugeniy L. Yakovis ${ }^{1, *}$, Anna V. Artemieva ${ }^{1}$, Mikhail V. Fokin ${ }^{2}$, \\ Marina A. Varfolomeeva ${ }^{1}$, Natalia N. Shunatova ${ }^{1}$ \\ ${ }^{1}$ Invertebrate Zoology Department, St.-Petersburg State University, Universitetskaya nab. 7/9, 199034 St. Petersburg, Russia \\ ${ }^{2}$ White Sea Biological Station, Zoological Institute RAN, Universitetskaya nab. 1, 199034 St. Petersburg, Russia
}

\begin{abstract}
The physical structure of a habitat strongly affects species composition and diversity in benthic assemblages. In the shallow subtidal zone in the White Sea in northwestern Russia, barnacles Balanus crenatus are often found in clusters on empty bivalve shells or small stones, sometimes overgrown by solitary ascidians (mainly Styela spp. and Molgula spp.). These epibenthic patches are surrounded with muddy sediment. Sediment also fills the space between barnacle shells within the patches. The assemblages of mobile macrofauna associated with epibenthic patches and surrounding unstructured sediment are different in species composition and abundance. We hypothesised that epibenthic patches at least partially affect mobile benthic organisms with their architectural properties as complex cavity-loaded structures. In a field experiment we assessed the strength of this effect, comparing unmanipulated natural epibenthic patches (E), unmanipulated patches of bare sediment (S), and patches of bare sediment with artificial imitation structures (mimics) added (M). Mimics were made of polyvinyl chloride (PVC) tubes and exposed for 1 and 2 yr (half-buried in sediment; 50 tubes $\times 8$ to 9 sets $\times 2$ replications). After 1 or 2 yr of exposure, the assemblages in $\mathrm{E}$ and $\mathrm{M}$ were much more similar to each other than to $\mathrm{S}$ (analysis of similarities, non-metric multidimensional scaling). Most species that were constantly abundant in E responded positively to the treatments. The bivalve Musculus discors and the sigalionid polychaete Pholoe minuta dominated numerically both in E and M, whereas maldanid Rhodine loveni and spionid-like Apistobranchus tullbergi dominated in S. Like many other large aggregated benthic suspension feeders, patched barnacles shape the associated assemblage of mobile benthic fauna with their architectural effect.
\end{abstract}

KEY WORDS: Habitat structure $\cdot$ Structural complexity $\cdot$ Barnacles $\cdot$ Ascidians $\cdot$ Soft bottoms

\section{INTRODUCTION}

Facilitation is one of the key processes structuring sea bottom landscapes. It commonly happens between strong environment modifiers, called foundation species, and the rest of the assemblage (Bruno \& Bertness 2001). Important benthic foundation species, like corals, seagrasses, mussels or oysters, are ecosystem engineers as they affect communities through habitat generation and modification. The relatively complex architecture of their reefs and beds influences other species to the same extent as their direct effects (Jones et al. 1994). Variation in habitat structure (either of biogenic or abiotic nature) generates abundance and diversity patterns in numerous systems studied (see Beck 2000, Kelaher 2003, Hewitt et al. 2005, and references therein) affecting recruitment and survival of benthic organisms. McCoy \& Bell (1991) suggested quantifying habitat structure in terms of 'habitat complexity' and 'habitat heterogeneity'. These factors stand for the absolute abundance of structural components and the relative abundance of different compo- 
nents at a certain spatial scale, respectively. With rare exceptions (Kelaher 2003), increased habitat complexity leads to an increase in diversity of the associated assemblages, which is generally believed to result from expansion of range of possible niches (MacArthur \& MacArthur 1961)

In case of the biogenic source of increased complexity, it is important to separate this architectural effect on the community structure from the direct biotic effects such as competition, predation and facilitation not mediated by physical habitat structures. This separation of effects is best achieved by experiments in which artificial imitation structures (mimics) are added to a habitat and the effect is compared with that of a foundation species. The results often prove that habitat modifiers such as mussels, which affect their environment by biodeposition (Kautsky \& Evans 1987, Hatcher et al. 1994), have comparable or even stronger effects on the associated assemblages because of their architectural properties, including increased habitat complexity and heterogeneity (Crooks \& Khim 1999, Ragnarsson \& Raffaelli 1999). Pattern generation by biogenic structures has been widely explored in imitation experiments with mangroves, coralline algal turfs, seagrasses, kelp, tube-building polychaetes and amphipods (Woodin 1978, Eckmann et al. 1981, Beck 2000, Lee et al. 2001, Norderhaug et al. 2002, Callaway 2003, Kelaher 2003 and references therein). The effect of imitation barnacle shells has been tested on sessile epibionts (Dean 1981) and indicated the enhancement of secondary colonisers. Live barnacles and their mimics similarly attracted principal sessile taxa (mussels and tunicates). However, the effect of barnacle mimics on mobile benthic infauna and epifauna in soft bottom communities has been never assessed.

Soft bottom landscapes with small solid substrates scattered over the unstructured sediment are reported from different subtidal locations (see Taylor \& Wilson 2003, Hewitt et al. 2005) and are also common in the White Sea in northwestern Russia (Yakovis et al. 2004). At our research sites the source of hard substrates is apparently confined to empty shells supplied by dying bivalves (particularly Serripes groenlandicus) and dropstones that arrive from melting ice in spring. Barnacles Balanus crenatus occupy most of these substrates, being commonly overgrown by solitary ascidians Styela spp., Molgula spp. and Boltenia echinata. Barnacle clusters consist of live individuals and their empty shells with muddy sediment filling all the cavities (Yakovis et al. 2004, 2005). Empty barnacle shells appear to persist there for years.

Aggregated barnacles and ascidians in soft bottoms are small-scale pattern generators (Yakovis et al. 2004,
2005). The assemblage of mobile taxa within the patches is different from that in the surrounding unstructured sediment and much less spatially variable at the scale of $\sim 1000 \mathrm{~m}$. The abundance of individual dependent species correlates with different properties of the patches (numbers of live barnacles, their empty shells and ascidians) (Yakovis et al. 2005). However, the processes underlying these associations remain unknown. Similar to other ecosystem engineers, aggregated barnacles and ascidians may combine architectural and purely biological effects on mobile fauna. The goal of the present study was to assess the relative strength of the architectural effects of aggregated barnacles, live and dead. Significant positive correlations previously observed between the numbers of large empty barnacle shells and abundances of several dominant mobile taxa (Yakovis et al. 2005) suggested these effects are important in structuring habitat for the latter.

We hypothesised that at least several mobile taxa of those associated with epibenthic patches are attracted to barnacle aggregations by their complex architectural structure, which is absent in the surrounding sediment. The prediction from this hypothesis was that habitat mimics (M) of increased complexity added to unstructured sediment would develop an assemblage of mobile taxa more similar to that observed in natural epibenthic patches (E) than in adjacent unstructured sediment (S). The difference between the assemblages associated with $\mathrm{M}$ and $\mathrm{E}$ would thus reflect the contribution of non-architectural effects into pattern generation.

\section{MATERIALS AND METHODS}

Study site. The study site was located $100 \mathrm{~m}$ southwest from the small island Pesya Luda (in the Solovetskiy Archipelago located in Onega Bay of the White Sea). The same place was defined as 'Site 1' in Yakovis et al. (2005). The depth was $12 \mathrm{~m}$ and the bottom temperature was 5 to $9^{\circ} \mathrm{C}$. The sediment was muddy sand with mean $( \pm \mathrm{SE})$ total organic matter content $0.84 \pm 0.002 \%$ (loss on ignition of dried sediment at $510^{\circ} \mathrm{C}$ for $10 \mathrm{~h}$ ). There were $20.8 \pm 1.8 \mathrm{~m}^{-2}$ hard particles (small stones or shells) noticeable to a diver on the sediment surface. For the experiments we used the area of about $25 \mathrm{~m}^{2}$ around the position $65^{\circ} 01.2^{\prime} \mathrm{N}, 35^{\circ} 39.7^{\prime} \mathrm{E}$.

Experiments. To imitate the complex cavity-loaded structure of barnacle clusters, we used bunch-like blocks of polyvinyl chloride (PVC) tubes, 40 to 50 tubes (105 $\mathrm{mm}$ long, $5 \mathrm{~mm}$ in diameter) per block, halfburied in unstructured sediment so that the tubes were positioned vertically. Blocks of tubes were set up in a 
haphazard pattern in July 2002 (8 blocks) and 2004 (9 blocks) and these replicate sets were exposed for 2 and $1 \mathrm{yr}$, respectively. The difference in exposure time between the 2 years resulted from logistical constraints and, as it turned out (as discussed later), had a relatively weak effect on mobile fauna attracted by mimics. Each block covered 14 to $23 \mathrm{~cm}^{2}$ of the bottom. The distance between the blocks was not less than $0.5 \mathrm{~m}$. No defaunation was performed on manipulated patches. The same $25 \mathrm{~m}^{2}$ area was sampled randomly with a $55 \mathrm{~cm}^{2}$ (8 cm deep) core in July of 2002 (32 samples), 2003 (17 samples), 2004 (10 samples) and 2005 (10 samples). After habitat mimics were collected in 2004 and 2005, each block was disassembled and cleared from sediment and processed like a sediment core. Sediment from cores and mimics was sieved through $0.5 \mathrm{~mm}$ mesh. Samples were sorted immediately and all mobile organisms were counted and wetweighed. Organisms were identified to species level with the exception of amphipods and isopods.

Natural epibenthic patches based on shells and small stones were collected within the $400 \mathrm{~m}^{2}$ area centred in the experimental plot. Each year (1999 to 2005) we collected all visible hard substrates from 2 randomly chosen $1.44 \mathrm{~m}^{2}$ plots (552 substrates in total). Substrates were examined in the laboratory with all sessile and mobile macrobenthic organisms identified to species level and counted, and all mobile organisms were also wet-weighed. We individually measured live barnacles and their empty shells (carino-rostral aperture length) and individually weighed solitary ascidians. Total weight was recorded for barnacles, red algae and an entire epibenthic patch.

Data analysis. To detect the effect of experimental structures added to a habitat on individual species, we used 3-factor type III sum of squares factorial ANOVA on densities according to a Before-After ControlImpact (BACI) design (Green 1979). Time (BeforeAfter) and treatment (Control-Mimics) were the first 2 factors. Sediment cores obtained among the blocks of tubes in 2002 and 2004 (15 cores) were used as the Before-Impact group and cores from the surrounding areas were used as Before-Control (2002 and 2004, 34 cores) and After-Control (2004 and 2005, 18 cores) groups. Two runs of the experiment (ending in 2004 and 2005) were the levels of the third factor. A significant time $\times$ treatment interaction term indicated the effect of manipulation. The destructive procedure of collecting Impact samples together with logistic constraints did not allow us to use 'Beyond BACI' designs (Underwood 1992) to compare the long-term processes in affected and unaffected habitats. However, the long-term annual data (1998 to 2006; 12 to $7655 \mathrm{~cm}^{2}$ cores per year) for the reference community were available, which made it possible to verify the BACI results at least by comparing the variance potentially caused by manipulation with interannual changes in the undisturbed habitat.

Shannon-Wiener diversity indices ( $\log _{e}$ ) were calculated for all samples. We applied type III sum of squares ANOVA to test the effect of microhabitat on the diversity index, followed by Tukey's HSD post hoc test for pairwise means comparison. We used 2-way analysis of similarities (ANOSIM, Clarke 1993) to reveal the relative strength of the effects of habitat type (S, M and E) and replication (2004 and 2005) on the assemblages. The analysis was based on the BrayCurtis dissimilarity index calculated on standardised densities. Species that were mainly responsible for the significant difference between the assemblages were identified with SIMPER procedure (Clarke 1993). The relationship between the assemblages associated with different natural and experimental microhabitats was visualised using non-metric multidimensional scaling (nMDS, Clarke 1993). All mean values are given as mean $\pm \mathrm{SE}$.

\section{RESULTS}

\section{Total abundance, domination and diversity}

In total, 89, 152 and 65 mobile species were found in $\mathrm{S}, \mathrm{E}$ and $\mathrm{M}$ habitat types, respectively. In all of the microhabitats polychaetes dominated in terms of relative density $(86 \%, 47 \%$ and $67 \%)$ and taxonomic richness $(78,72$ and 43 species in $S, E$ and $M$, respectively). Average number of mobile species per sample was $19.9 \pm 0.5$ in $\mathrm{S}, 12.4 \pm 0.7$ in $\mathrm{E}$ and $14.2 \pm 1.2$ in $\mathrm{M}$ (significant effect of microhabitat; ANOVA: p < 0.001, $F=259.2$ ); a significant difference existed between $\mathrm{S}$ and E (Tukey's HSD test, $\mathrm{p}<0.001$ ). Mean ShannonWiener species diversity index $\left(H^{\prime}\right)$ for mobile taxa was $2.62 \pm 0.02$ in $\mathrm{S}, 1.56 \pm 0.04$ in $\mathrm{E}$ and $2.12 \pm 0.08$ in $\mathrm{M}$ (ANOVA: $\mathrm{p}<0.001, F=277.8$ ). We treated each separate hard fragment as a stand-alone epibenthic patch, but many of them were rather small, especially those that lacked primary substrate. Exclusion of these small substrate-less patches resulted in an $H^{\prime}$ value of $1.67 \pm 0.05$ for mobile fauna diversity in $\mathrm{E}$. Regardless of the latter correction, a significant pairwise difference was observed only between the $H^{\prime}$ values in E and S (Tukey's HSD test, p < 0.001). The $H^{\prime}$ value for $\mathrm{E}$ based both on mobile and sessile taxa was $2.22 \pm 0.04$.

The bivalve Musculus discors and the sigalionid polychaete Pholoe minuta dominated numerically both in E and M, whereas maldanid Rhodine loveni and spionid-like Apistobranchus tullbergi dominated in $\mathrm{S}$. 


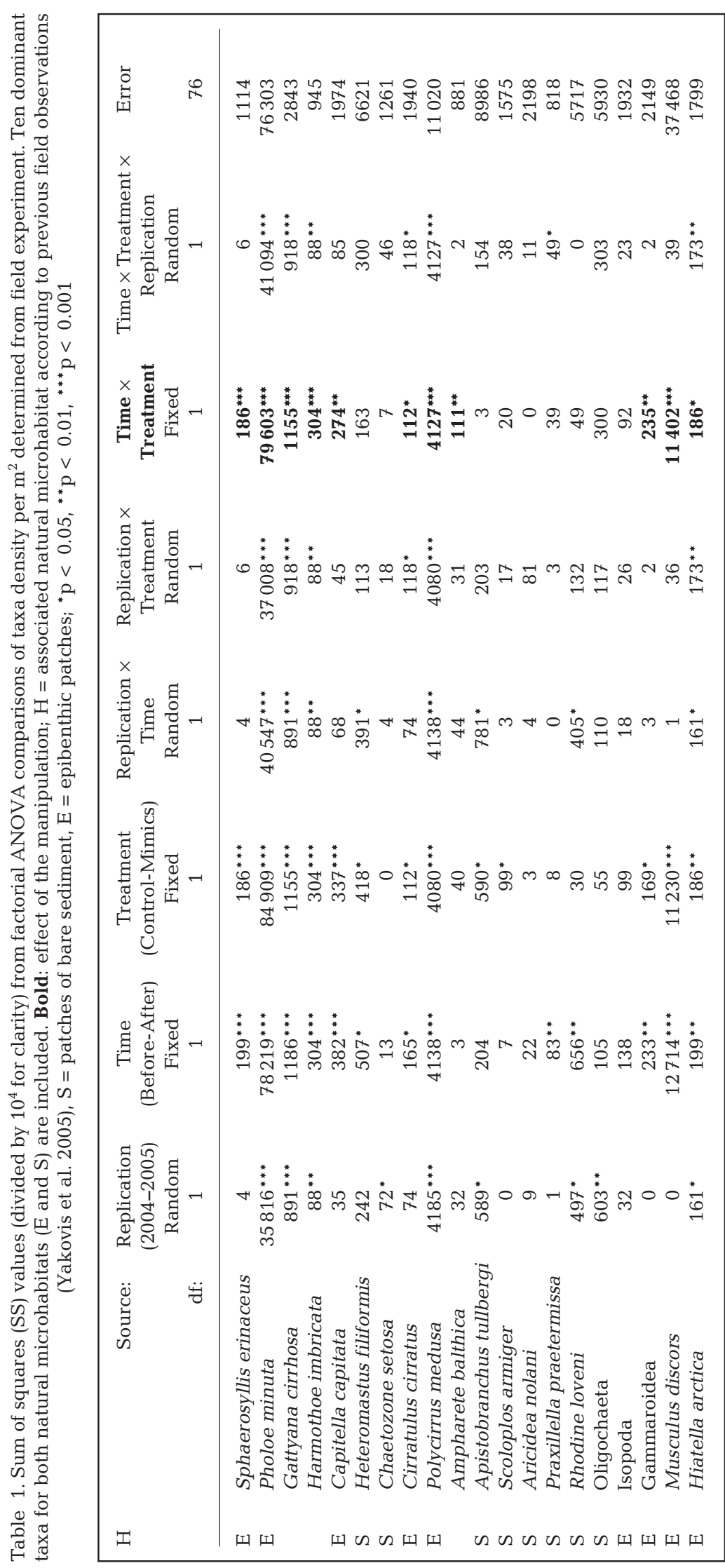

\section{Abundance of individual species}

According to the results of ANOVA on absolute densities (Table 1), 11 dominant species out of 20 were significantly affected by habitat mimics (interaction Before-After $\times$ Control-Mimics, $p<0.05$ ). Of these 11 species, 8 are common inhabitants of natural epibenthic patches, and of the remaining 9 species, 8 are associated with unstructured sediment (as observed by Yakovis et al. 2005). This gives $80 \%$ match between the results of the experiment and the observed species distribution between microhabitats. However, species that dominated in unmanipulated bare sediment generally gave no significant response to manipulations. Compared with long-term variation of their density in natural microhabitats, most dominant taxa were similarly abundant in E and $M$ (Table 2).

On the nMDS plot (Fig. 1), samples grouped according to microhabitat type with no difference between the years despite the different exposure terms for the runs 2004 and 2005. Samples of bare sediment grouped separately. Experimental mimics grouped together with natural epibenthic patches. ANOSIM results were consistent with this pattern: the difference between sediment cores and any of the complex patches ( $\mathrm{E}$ and $\mathrm{M})$ was much higher $(\mathrm{R}=0.93, \mathrm{p}<0.001$ and $\mathrm{R}=0.97, \mathrm{p}<0.001$, respectively) than between the mimics and natural epibenthic patches $(R=0.28, p=0.08)$. The effect of the year was insignificant $(\mathrm{R}=$ $0.002, p=0.46$ ).

Epibenthic patches dominated by ascidians were less similar to artificial ones than the patches dominated by barnacles (Fig. 2). ANOSIM also supported this result: $\mathrm{R}$ was 0.24 between $\mathrm{M}$ and barnacle-dominated patches $\left(E_{B}\right)$, whereas ascidian-dominated $\left(\mathrm{E}_{\mathrm{A}}\right)$ patches resulted in $R=0.40$. From this ANOSIM we excluded all the natural patches with the total biomass of barnacles and ascidians less than $3 \mathrm{~g}$ (white markers on the nMDS plot on Fig. 2). We assumed that trying to assess the effect of domination in smallest patches (with only few mobile organisms) would just increase the bias. 


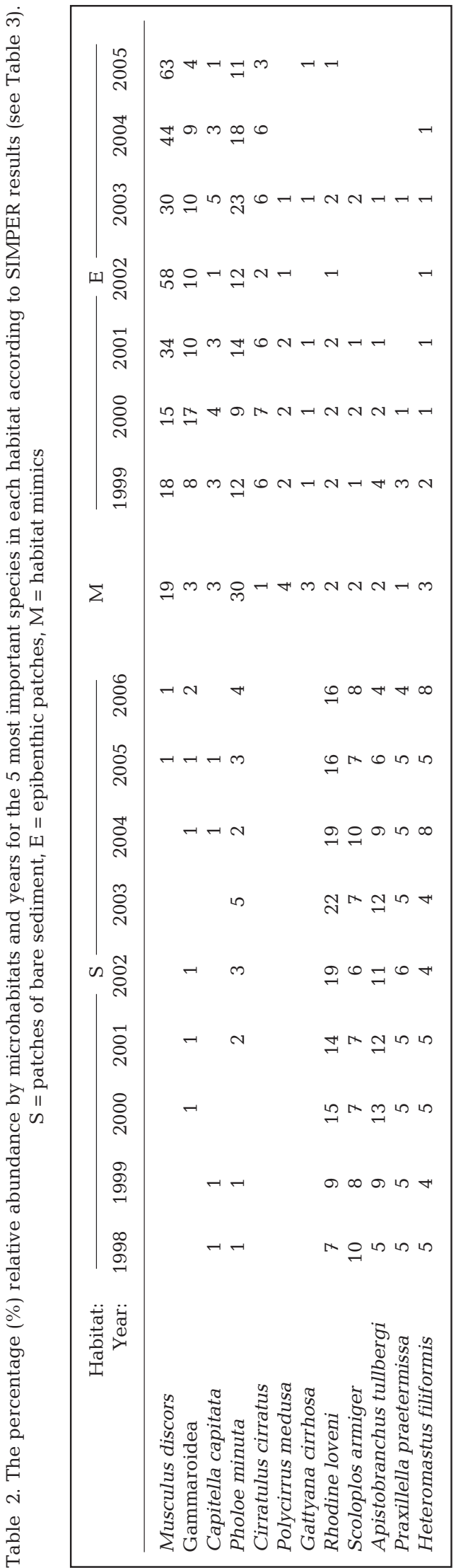

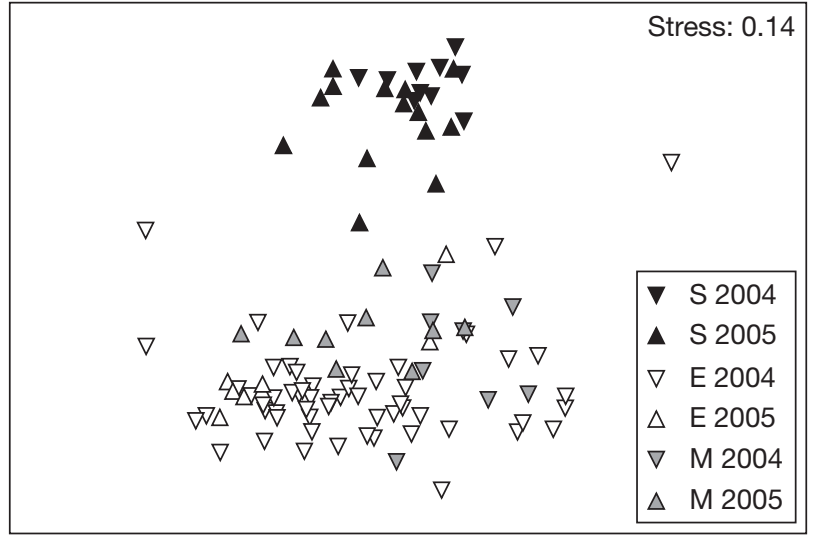

Fig. 1. nMDS ordination of similarities between assemblages of mobile species (Bray-Curtis dissimilarity, standardised abundance); samples indicated by microhabitat and year. $\mathrm{S}=$ patches of bare sediment, $\mathrm{E}=$ epibenthic patches, $\mathrm{M}=$ habitat mimics. Samples from E and S obtained before 2004 removed for clarity

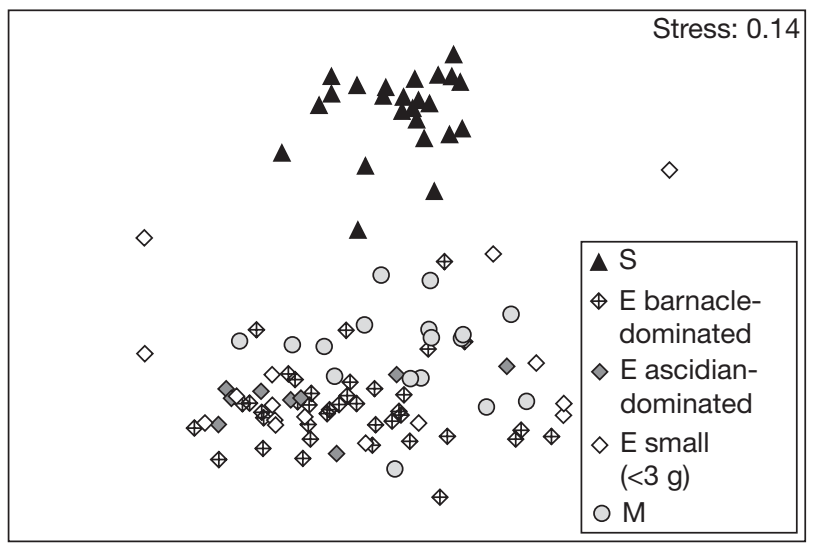

Fig. 2. nMDS ordination of similarities between assemblages of mobile species (Bray-Curtis dissimilarity, standardised abundance); samples indicated by type. $\mathrm{S}=$ patches of bare sediment, $\mathrm{E}=$ epibenthic patches (large barnacle or ascidian dominated and small; total weight $<3 \mathrm{~g}$ ), $\mathrm{M}=$ habitat mimics. Samples from E and S obtained before 2004 removed for clarity

According to SIMPER results, the largest overlap in important species lists (3 of 5) was observed between $\mathrm{M}$ and $\mathrm{E}$ (Table 3). There were no common important species in the pairs of assemblages S/M and S/E.

A relatively large bivalve Musculus discors was almost absent in $\mathrm{S}$. In $\mathrm{M}$ it was represented by smaller specimens than in $\mathrm{E}$ (individual mean weight $=0.3 \pm$ $0.1 \mathrm{mg}$ in $\mathrm{M}$ and $47.4 \pm 8.1 \mathrm{mg}$ in $\mathrm{E}_{\text {; }}$ Student's $t$-test, $\mathrm{p}<$ 0.001). Density of the largest benthic predator found, the spider crab Hyas araneus, was about 4 individuals $\mathrm{m}^{-2}$ in $\mathrm{S}$. 
Table 3. SIMPER results. The percentage (\%) contribution to average measures of dissimilarity between samples from each microhabitat ( $\mathrm{S}, \mathrm{E}$ and $\mathrm{M})$ and between microhabitats (S/E, S/M and E/M) for the 5 most important species for each comparison. $\mathrm{S}=$ patches of bare sediment, $\mathrm{E}=$ epibenthic patches, $\mathrm{M}=$ habitat mimics

\begin{tabular}{|lrrrrrr|}
\hline \multicolumn{1}{c}{ Habitat: } & S & E & M & S/E & S/M & E/M \\
\hline Musculus discors & & 43 & 20 & 16 & 10 & 18 \\
Gammaroidea & & 6 & & 4 & & 5 \\
Capitella capitata & & 2 & 3 & & & \\
Pholoe minuta & & 33 & 53 & 11 & 17 & 16 \\
Cirratulus cirratus & & 7 & & 4 & & 5 \\
Polycirrus medusa & & & 3 & & & 4 \\
Gattyana cirrhosa & 21 & & 3 & & & \\
Rhodine loveni & 11 & & & & 4 & \\
Scoloplos armiger & 10 & & & & 4 & \\
Apistobranchus tullbergi & 10 & & & & & \\
Praxillella praetermissa & 8 & & & & & \\
Heteromastus filiformis & 6 & & & & &
\end{tabular}

\section{DISCUSSION}

Initially we assumed that the difference in mobile fauna between the patches dominated by barnacles and ascidians and the patches of bare sediment resulted, at least in part, from the effect of specific physical structure, i.e. increased structural complexity associated with large aggregated epibenthic invertebrates. Consistent with the prediction, habitat mimics, intended to simulate the patches with high complexity after 1 or 2 yr of exposure, altered the composition of mobile fauna. The resulting assemblage was much closer to the one observed in natural epibenthic patches than to the one in unstructured sediment. Imitation structures and natural epibenthic patches shared the same dominant species but in different proportions.

The mimics we used were designed as a rather rough imitation of the natural epibenthic patches dominated by barnacles and ascidians. Structural heterogeneity of the natural patches was considerably higher. Most of them were composed at least of 4 types of elements: living barnacles, empty barnacle shells, ascidians and red algae. Several tiers were possible both in barnacles and in ascidians. Structural complexity, however, was higher in the imitation blocks since the average epibenthic patch studied usually had less than 50 relatively large elements of each type (E. L. Yakovis, A. V. Artemieva, N. N. Shunatova, M. A. Varfolomeeva unpubl.). The considerable similarity observed in mobile fauna attracted by notably different natural and artificial complex structures may indicate the generality of the effect. Although we did not reproduce the experiment at several sites with totally different species composition of infaunal assemblages, the following testable prediction can be made: in the White Sea shallow subtidal zone (or even in a wider range of related arctic bottom landscapes), the com- plex structures surrounded and partially filled by muddy sediment like barnacle clusters, ascidian clumps and probably kelp holdfasts often attract a similar and stable set of mobile taxa. This seems especially likely given that natural epibenthic patches develop the same assemblage of mobile taxa regardless of the surrounding species composition at least at a scale of $1000 \mathrm{~m}$ (Yakovis et al. 2005). Furthermore, according to the authors' unpublished results, Pholoe minuta considerably increased its abundance in response to addition of tube-like structures to a habitat within the shallow subtidal ( 0.5 to $1.0 \mathrm{~m}$ depth) where the unstructured sediment fauna was dominated by Tubificoides benedeni (Oligochaeta), Hydrobia ulvae (Mollusca, Gastropoda) and Heteromastus filiformis (Polychaeta).

Very little is known about the sensitivity of arctic subtidal mobile fauna to the presence of hard, complex, 3-dimensional structures in the sediment. The assemblages from temperate intertidal locations are studied much more often, yet the principal taxa found in them are rarely common with those at our research sites. Kensler \& Crisp (1965) experimented in the intertidal zone with $5 \mathrm{~mm}$ wide artificial crevices exposed for $2 \mathrm{yr}$, and observed that Cirratulus cirratus was among the constant arrivals to those crevices that were filled with mud. However, Pholoe minuta, although also present in local fauna, was rare in crevice mimics. Crevices are a common natural microhabitat for C. cirratus (Olive 1970). Early works revealed positive thygmotaxis in some cirratulids (Flattely 1916): worms indicated a strong preference for the microhabitats allowing physical contact with solid surfaces. Callaway (2003), who ran long-term experiments with tube-like structures on the intertidal sandflat, reported increased abundance of Capitella capitata in samples from the plots where mimics had been added to the habitat.

The presence of tube-like structures in soft sediment can generally affect 4 main factors potentially important for mobile organisms: soft sediment properties, the hydrodynamic regime, the availability of refuge from predation (see Callaway 2003) and the presence of solid surfaces to attach tubes and similar selfconstructed objects. The reduction in current velocity locally increases the deposition rate (Eckmann et al. 1981, Friedrichs et al. 2000). This factor is used to explain high relative abundances, demonstrated in plots with imitation tubes, of opportunistic species positively sensitive to organic enrichment such as capitellid polychaetes (Callaway 2003). Increased densities of 
meiofauna among the tubes can attract small predators that feed on them (Peachey \& Bell 1997). For example, numerous harpacticoid copepods are often found in the stomachs of Harmothoe imbricata from the White Sea shallow subtidal zone (A. E. Gornykh \& V. M. Khaitov unpubl. data).

Tubes may protect potential prey from larger predators (Woodin 1978), including crabs and fishes, which often have an important structuring effect on benthic communities (Hindell et al. 2001, Quijón \& Snelgrove 2005 and references therein). This refuge-providing role of natural and artificial structures is likely to govern the spatial distribution of the sigalionid Pholoe minuta. Indeed, field and laboratory experiments clearly demonstrate that predation by crabs limits the abundance of a similar species, Pholoe tecta, in unstructured sediment (Quijón \& Snelgrove 2005).

Many benthic amphipods need solid structures to which they can attach their tubes or 'mud whips' (Mattson \& Cedhagen 1989). Adult Musculus discors are sessile; in $\mathrm{E}$ they reside in ascidian clumps either in the nests made of byssi or embedded in ascidian tunicae (see Bertrand 1971). Smaller ones, such as those found in $\mathrm{M}$, are mobile. However, they are expected to choose microhabitats potentially suitable for adults, which need hard substrates to anchor themselves with byssus as shown for other mytilids (e.g. Young 1983).

Habitat mimics attracted more Pholoe minuta and fewer Musculus discors compared with natural epibenthic patches; generally, the assemblage in $M$ was closer to that from barnacle-dominated patches. M. discors is strongly associated with ascidians and its abundance positively correlates with ascidian biomass (Yakovis et al. 2005). Yet the mimics we used imitated barnacle clusters rather than ascidian clumps, which is consistent with the difference observed in assemblages.

Nearly all the taxa found in E and M could also be found in the surrounding bare sediment, but infrequently and generally at lower densities (Yakovis et al. 2005). It is, therefore, possible that they are recruited to the imitation plots from their immediate surroundings. This colonisation strategy is the only one for the arrivals with direct development (like Cirratulus cirratus, see Petersen 1999) and one of the alternatives for those with planktonic larvae (like Capitella capitata and Pholoe minuta, see Mileikovsky 1968, Butman \& Grassle 1992). Higher relative abundance of $P$. minuta in $M$ compared with that in E could thus possibly be due to larval depletion by barnacles or ascidians, though previously observed effects of both suspension feeders on recruitment of coexisting taxa were rather weak (Young \& Gotelli 1988, Young 1989).

Musculus, however, may be an exception. Young mobile mussels strongly prefer hard substrates (Young 1983) since their adults need a basis to attach byssus, and this is probably the same with $M$. discors. Blue mussel Mytilus edulis plantigrades are poor crawlers on soft sediment; they usually float on byssus from one hard substrate to another instead (S. Dobretsov, pers. comm.). Unlike many other mytilids, Musculus discors lacks planktonic larvae and develops directly with the distribution proceeding by byssus-assisted floating of plantigrades (Martel \& Chia 1991). These findings, together with the observed absence of $M$. discors in $\mathrm{S}$, suggest that these bivalves accumulate in $\mathrm{E}$ and $\mathrm{M}$ with the help of the flow, not by crawling.

Mobile fauna attracted to complex structures partially buried in soft sediment are probably composed of (1) opportunistic species sensitive to organic enrichment (e.g. Capitella capitata), (2) species that, though mobile, nevertheless stick to solid surfaces to dwell on or attach their tubes or 'mud whips' (Musculus discors and probably some amphipods), (3) species that are limited elsewhere by large predators (Pholoe minuta) and (4) predators of meiofauna or some of the species mentioned (possibly Gattyana cirrosa or Harmothoe imbricata).

Mobile fauna demonstrated a similar order of sample (alpha) diversity (Whittaker 1965) in all types of manipulated and intact microhabitats. A relatively high diversity in samples from $\mathrm{S}$ can be attributed to smallscale complexity increased by dominance of the tubebuilding maldanids Rhodine loveni and Praxillella praetermissa (see Woodin 1978). However, complex hard structures in E developed assemblages strongly different in species composition and relative abundances from those associated with the surrounding sediment, thereby increasing the beta diversity (the within-habitat species turnover, see Peet 1974) within the whole habitat, as predicted by Hewitt et al. (2005).

We conclude that the epibenthic patches dominated by Balanus crenatus and solitary ascidians attract an important part of the associated mobile macrofauna (Yakovis et al. 2005) by increased habitat complexity, particularly by the presence of $5 \mathrm{~mm}$ and smaller cavities filled with muddy sediment. The mimics we used resembled the barnacle component of typical epibenthic patches, and the resulting assemblage was closer to that observed in barnacle-dominated rather than in ascidian-dominated aggregations. Like many other large suspension feeders, barnacles strongly affect the associated mobile fauna by the physical properties of their aggregations. Hard particles like shell debris or dropstones are often scattered over unstructured soft sediment, increasing the structural heterogeneity of these habitats and beta diversity of the associated assemblages (Hewitt et al. 2005). Occupying this kind of substrate, barnacles, together with the sessile assemblage they support (e.g. Dean 1981), may potentially produce similar structuring effects in different locations worldwide. 
Acknowledgements. None of our scientific affairs could ever be possible without our late teacher E. A. Ninbourg. We thank A. Grishankov (SPb State University) and numerous volunteers for their collaboration during field work, A. and N. Cherenkovy (Biological Station of Moscow State University) for technical support and accommodation, D. Tomanovskiy for his diving skills, O. Pronina (Polar Institute for Fisheries and Oceanography) for the compressed air, S. Dobretsov (University of Kiel) for discussions and assistance in data processing, and Statsoft, Inc. for a copy of the STATISTICA software package granted to SPb State University. Thanks to N. Lentsman (SPb State University) for the linguistic assistance and to 3 anonymous reviewers who made valuable comments on the manuscript. Financial support was provided by Russian Foundation for Basic Research (grant nos. 02-04-50020A, 05-04-48927A, 05-04-63041K, 06-04-63077K, 06-04-01854-E_B, 07-04-10075 K).

\section{LITERATURE CITED}

Beck MW (2000) Separating the elements of habitat structure: independent effects of habitat complexity and structural components on rocky intertidal gastropods. J Exp Mar Biol Ecol 249:29-49

Bertrand GA (1971) The ecology of the nest-building bivalve Musculus lateralis commensal with the ascidian Molgula occidentalis. Veliger 14:23-29

Bruno JF, Bertness MD (2001) Habitat modification and facilitation in benthic marine communities. In: Bertness MD, Gaines SD, Hay ME (eds) Marine community ecology. Sinauer, Sunderland, MA, p 201-218

Butman CA, Grassle JP (1992) Active habitat selection by Capitella sp. I larvae. 1. Two-choice experiments in still water and flume flows. J Mar Res 50:669-715

Callaway R (2003) Long-term effects of imitation polychaete tubes on benthic fauna: they anchor Mytilus edulis (L.) banks. J Exp Mar Biol Ecol 283:115-132

Clarke KR (1993) Non-parametric multivariate analyses of changes in community structure. Aust J Ecol 18:117-143

Crooks JA, Khim HS (1999) Architectural vs. biological effects of a habitat-altering, exotic mussel, Musculista senhousia. J Exp Mar Biol Ecol 240:53-75

Dean TA (1981) Structural aspects of sessile invertebrates as organizing forces in an estuarine fouling community. J Exp Mar Biol Ecol 53:163-180

Eckmann JE, Nowell ARM, Jumars PA (1981) Sediment destabilization by animal tubes. J Mar Res 39:361-374

Flattely FW (1916) Notes on the ecology of Cirratulus (Audouinia) tentaculatus (Montagu). J Mar Biol Assoc UK 11:60-70

Friedrichs M, Graf G, Springer B (2000) Skimming flow induced over a simulated polychaete tube lawn at low population densities. Mar Ecol Prog Ser 192:219-228

Green RH (1979) Sampling design and statistical methods for environmental biologists. Wiley, Chichester

Hatcher A, Grant J, Schofield B (1994) Effects of suspended mussel culture (Mytilus spp.) on sedimentation, benthic respiration and sediment nutrient dynamics in a coastal bay. Mar Ecol Prog Ser 115:219-235

Hewitt JE, Thrush SF, Halliday J, Duffy C (2005) The importance of small-scale habitat structure for maintaining beta diversity. Ecology 86:1619-1626

Hindell JS, Jenkins GP, Keough MJ (2001) Spatial and temporal variability in the effects of fish predation on macrofauna in relation to habitat complexity and cage effects. Mar Ecol Prog Ser 224:231-250

Jones CG, Lawton JH, Shachak M (1994) Organisms as ecosystem engineers. Oikos 69:373-386

Kautsky N, Evans S (1987) Role of biodeposition by Mytilus edulis in the circulation of matter and nutrients in a Baltic coastal system. Mar Ecol Prog Ser 38:201-212
Kelaher BP (2003) Changes in habitat complexity negatively affect diverse gastropod assemblages in coralline algal turf. Oecologia 135:431-441

Kensler CB, Crisp DJ (1965) The colonization of artificial crevices by marine invertebrates. J Anim Ecol 34:507-516

Lee SY, Fong CW, Wu RSS (2001) The effects of seagrass (Zostera japonica) canopy structure on associated fauna: a study using artificial seagrass units and sampling of natural beds. J Exp Mar Biol Ecol 259:23-50

MacArthur RH, MacArthur JW (1961) On bird species diversity. Ecology 42:594-598

Martel A, Chia FS (1991) Drifting and dispersal of small bivalves and gastropods with direct development. J Exp Mar Biol Ecol 150:131-147

Mattson S, Cedhagen T (1989) Aspects of the behaviour and ecology of Dyopedos monacanthus (Metzger) and D. porrectus with comparative notes on Dulichia tuberculata Boeck (Crustacea: Amphipoda: Podoceridae). J Exp Mar Biol Ecol 127:253-272

McCoy ED, Bell SS (1991) Habitat structure: the evolution and diversification of a complex topic. In: Bell SS, McCoy ED, Mushinsky HR (eds) Habitat structure: the physical arrangement of objects in space. Chapman and Hall, New York, p 3-27

Mileikovsky SA (1968) Distribution of pelagic larvae of bottom invertebrates of the Norwegian and Barents seas. Mar Biol 1:161-167

Norderhaug KM, Christie H, Rinde E (2002) Colonisation of kelp imitations by epiphyte and holdfast fauna: a study of mobility patterns. Mar Biol 141:965-973

Olive PJW (1970) Reproduction of a Northumberland population of the polychaete Cirratulus cirratus. Mar Biol 5:259-273

Peachey RL, Bell SS (1997) The effects of mucous tubes on the distribution, behavior and recruitment of seagrass meiofauna. J Exp Mar Biol Ecol 209:279-291

Peet PK (1974) The measurement of species diversity. Annu Rev Ecol Syst 5:285-307

Petersen ME (1999) Reproduction and development in Cirratulidae (Annelida: Polychaeta). Hydrobiologia 402:107-128

Quijón PA, Snelgrove PVR (2005) Differential regulatory roles of crustacean predators in a sub-arctic, soft-sediment system. Mar Ecol Prog Ser 285:137-149

Ragnarsson SA, Raffaelli D (1999) Effects of the mussel Mytilus edulis L. on the invertebrate fauna of sediments. J Exp Mar Biol Ecol 241:31-43

Taylor PD, Wilson MA (2003) Palaeoecology and evolution of marine hard substrate communities. Earth Sci Rev 62:1-103

Underwood AJ (1992) Beyond BACI: the detection of environmental impacts on populations in the real, but variable, world. J Exp Mar Biol Ecol 161:145-178

Whittaker RH (1965) Dominance and diversity in land plant communities. Science 147:250-260

Woodin SA (1978) Refuges, disturbance, and community structure: a marine soft-bottom example. Ecology 59:274-284

Yakovis EL, Artemieva AV, Fokin MV (2004) Spatial pattern indicates an influence of barnacle and ascidian aggregations on the surrounding benthic assemblage. J Exp Mar Biol Ecol 309:155-172

Yakovis EL, Artemieva AV, Fokin MV, Grishankov AV, Shuntova NN (2005) Patches of barnacles and ascidians in soft bottoms: associated motile fauna in relation to the surrounding assemblage. J Exp Mar Biol Ecol 327:210-224

Young GA (1983) The effect of sediment type upon the position and depth at which byssal attachment occurs in Mytilus edulis. J Mar Biol Assoc UK 63:641-651

Young GA (1989) Larval depletion by ascidians has little effect on settlement of epifauna. Mar Biol 102:481-489

Young GA, Gotelli NJ (1988) Larval predation by barnacles: effects on patch colonization in a shallow subtidal community. Ecology 69:624-634 